\title{
Effect of dietary methionine on tissue selenium and glutathione peroxidase $(E C 1.11 .1 .9)$ activity in rats given selenomethionine
}

\author{
BY INGO H. WASCHULEWSKI AND ROGER A.SUNDE* \\ Department of Nutrition and Food Science, and Nutritional Sciences Program, University \\ of Arizona, Tucson, AZ 85721, USA
}

(Received 5 January 1988 - Accepted 18 February 1988)

\begin{abstract}
1. The effect of dietary methionine on the utilization of selenium from dietary selenomethionine ([Se]Met) for tissue Se deposition and for glutathione peroxidase (EC 1.11.1.9; GSH-Px) synthesis was studied in male weanling rats.

2. When rats were given $0.5 \mathrm{mg}$ Se as [Se]Met $/ \mathrm{kg}$ diet supplemented with 0,4 or $9 \mathrm{~g}$ methionine $/ \mathrm{kg}$, Se in plasma, erythrocytes, liver and muscle increased significantly over the $20 \mathrm{~d}$ period for all methionine-treatment groups. The increases in erythrocyte and muscle Se, however, were significantly higher in rats fed on the methionine-deficient diet compared with the methionine-supplemented diets.

3. In contrast to the increases in tissue Se, GSH-Px activity in liver, plasma and muscle decreased in methioninedeficient rats given $0.5 \mathrm{mg}$ Se as [Se]Met $/ \mathrm{kg}$ whereas GSH-Px activity was maintained or increased in rats supplemented with methionine.

4. The percentage of tissue Se associated with GSH-Px was calculated from the measured Se concentration and GSH-Px activity. A significantly lower percentage of Se was associated with GSH-Px in methionine-deficient rats compared with methionine-supplemented rats.

5. These results show that Se from dietary [Se]Met is preferentially incorporated into body proteins rather than used for GSH-Px synthesis when methionine is limiting in the diet.

6. These results further suggest that [Se]Met might not be the optimum Se compound to use for Se supplementation because metabolism of dietary [Se]Met to a biochemically active form, such as GSH-Px, was impaired when [Se]Met was provided in diets low in methionine.
\end{abstract}

The metabolism of selenium is an important factor when considering the bioavailability of different dietary forms of Se. Both inorganic forms of Se such as selenite and organic forms such as selenomethionine ([Se]Met) are readily absorbed from the diet (McConnell \& Cho, 1965; Thomson \& Stewart, 1973; Humaloja \& Mykkanen, 1986). The retention of the absorbed Se, however, will depend on Se metabolism as well as absorption, and the conversion of Se to biochemically active Se species will determine whether or not an adequate concentration of Se is present in the tissue. In general, selenite and [Se]Met have been reported to have similar effects on the activity of the Se-dependent enzyme glutathione peroxidase (EC 1.11.1.9; GSH-Px) in both animals (Hafeman et al. 1974; Chow \& Tappel, 1974; Omaye \& Tappel, 1974; Pierce \& Tappel, 1977) and man (Thomson et al. 1982). Some experiments, however, have reported higher tissue Se deposition from [Se]Met than from selenite (Cary et al. 1973; Robinson et al. 1978; Thomson et al. 1982), and one report has suggested that these two forms of supplemental Se can have decidedly different metabolic fates (Sunde et al. 1981 a).

[Se]Met, the Se-containing analogue of methionine, is thought to be the common form of Se in foodstuffs of plant origin, and [Se]Met is a common form of Se used for human supplementation. As indicated previously, [Se]Met supplementation will increase tissue $\mathrm{Se}$ levels substantially, and this tissue Se has been shown to be present as [Se]Met when high levels of [Se]Met are administered (Beilstein \& Whanger, 1986). The form of Se in tissue when low to moderate levels of [Se]Met are given, however, has not been demonstrated to be [Se]Met. 
Sunde et al. (1981 a) reported that Se availability for GSH-Px synthesis from dietary [Se]Met was reduced when supplemented at less than $0.5 \mathrm{mg} \mathrm{Se} / \mathrm{kg}$ in rats fed on a methionine-deficient diet. These workers suggested that [Se]Met had been preferentially incorporated into body proteins when methionine was limiting. This hypothesis was also supported by our recent study which investigated the effect of dietary methionine level on the utilization of stored tissue Se originating from dietary [Se]Met (Waschulewski \& Sunde, 1988). In that study, weanling rats were given $0.5 \mathrm{mg} \mathrm{Se}$ as [Se]Met $/ \mathrm{kg}$ in a methioninedeficient diet for $21 \mathrm{~d}$, and tissue GSH-Px activity decreased substantially in spite of increased tissue Se levels. When the rats were switched to an Se-deficient diet, tissue GSHPx activities increased transiently if the diet was supplemented with adequate or high levels of methionine, suggesting that additional methionine increased the utilization of the deposited tissue Se for GSH-Px synthesis.

To characterize further the effect of dietary methionine on [Se]Met metabolism, weanling rats were given $0.5 \mathrm{mg} \mathrm{Se}$ as [Se]Met $/ \mathrm{kg}$ with deficient $(0 \mathrm{~g} / \mathrm{kg})$, adequate $(4 \mathrm{~g} / \mathrm{kg})$ or high $(9 \mathrm{~g} / \mathrm{kg})$ levels of dietary methionine for $20 \mathrm{~d}$. We found that tissue Se increased significantly when rats were given $0.5 \mathrm{mg} \mathrm{Se}$ as [Se] Met $/ \mathrm{kg}$ regardless of the methionine treatment, and that erythrocyte and muscle Se concentrations were significantly higher in methionine-deficient rats compared with methionine-supplemented rats. In contrast to the effect on tissue Se, GSH-Px activity in plasma, liver and muscle decreased significantly when rats were supplemented with $0.5 \mathrm{mg}$ Se as [Se] Met $/ \mathrm{kg}$ in a methionine-deficient diet, whereas GSH-Px activity remained the same or increased in rats supplemented with methionine.

\section{MATERIALS AND METHODS}

\section{Animals and diets}

Male 22-d-old weanling rats (Holtzman Co., Madison, WI) weighing 60-70 g were housed individually in hanging wire-mesh cages. Diet and deionized water were provided ad lib. The basal diet, described previously by Knight \& Sunde (1987), is given in Table 1 . The diet was supplemented with $100 \mathrm{mg}$ DL- $\alpha$-tocopheryl acetate $/ \mathrm{kg}$ (Sigma Chemical Co., St Louis, $\mathrm{MO}$ ) at the expense of sucrose to prevent liver necrosis. Amino acid analysis indicated that the basal diet contained $1.7 \mathrm{~g}$ methionine and $1.4 \mathrm{~g}$ cysteine $/ \mathrm{kg}$ (Waschulewski \& Sunde, 1988 ), thus providing only $50 \%$ of the dietary sulphur amino acid requirement of the growing rat (National Research Council, 1978). The basal diet contained less than $0.02 \mathrm{mg}$ $\mathrm{Se} / \mathrm{kg}$ as determined by fluorometric analysis (Waschulewski \& Sunde, 1988).

\section{Experimental design}

The weanling rats, shipped by air express to Arizona, were fed on an Se-adequate, methionine-adequate diet $(0.2 \mathrm{mg}$ Se as selenite $/ \mathrm{kg}, 4 \mathrm{~g}$ supplemental DL-methionine $/ \mathrm{kg})$ overnight. The rats were then randomly divided into thirteen groups, each containing six rats, and one group was killed (day 0 ) to provide initial values. The remaining groups were all fed on the basal diet supplemented with $0.5 \mathrm{mg}$ Se as DL-selenomethionine (Sigma Chemical Co.) $/ \mathrm{kg}$ diet. The diet was further supplemented with 0,4 or $9 \mathrm{~g}$ DL-methionine (US Biochemical Corp., Cleveland, $\mathrm{OH}$ ) $/ \mathrm{kg}$; four groups/methionine level, thus providing approximately 50,100 or $200 \%$ respectively of the dietary sulphur amino acid requirement of the rat (National Research Council, 1978). At 3, 6, 13 and 20 d after the start of [Se]Met supplementation, one group receiving each dietary methionine treatment was killed and the tissues analysed.

\section{Analyses}

Rats were anaesthetized with diethyl ether and blood was drawn by cardiac puncture using a heparinized syringe. Plasma was separated from erythrocytes by centrifugation $(1000 \mathrm{~g}$ 
Table 1. Composition of basal diet

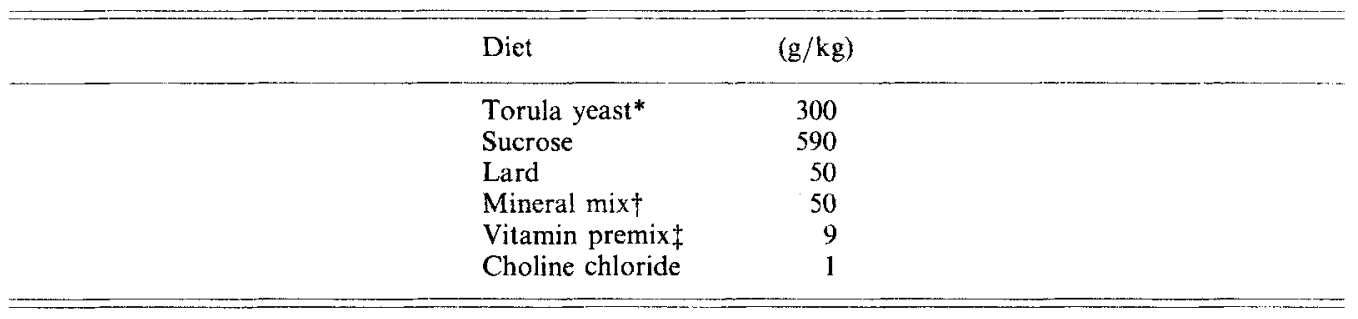

* Rhinelander Paper Co., Rhinelander, WI, USA.

$\dagger$ Mineral mix (g/kg mix): $\mathrm{CaCO}_{3} 526 \cdot 76, \mathrm{MgCO}_{3} 25 \cdot 0, \mathrm{MgSO}_{4} \cdot 7 \mathrm{H}_{2} \mathrm{O} 32 \cdot 76, \mathrm{NaCl} 69 \cdot 0, \mathrm{KCl} 108 \cdot 0, \mathrm{KH}_{2} \mathrm{PO}_{4}$ $212 \cdot 0$, ferric ammonium citrate-green $20 \cdot 5$, $\mathrm{KI} 0 \cdot 08, \mathrm{MnSO}_{4} \cdot \mathrm{H}_{2} \mathrm{O} 3 \cdot 33, \mathrm{NaF} 1 \cdot 00, \mathrm{AlNH}_{4}\left(\mathrm{SO}_{4}\right)_{2} \cdot 12 \mathrm{H}_{2} \mathrm{O} 0 \cdot 16$, $\mathrm{CuSO}_{4} \cdot 5 \mathrm{H}_{2} \mathrm{O} 0 \cdot 90, \mathrm{CrCl}_{3} \cdot 6 \mathrm{H}_{2} \mathrm{O} 0 \cdot 51$.

$\ddagger$ Vitamin premix $(\mathrm{mg} / \mathrm{kg}$ diet): glucose monohydrate $8757 \cdot 45$, thiamin hydrochloride $4 \cdot 0$, riboflavin $2 \cdot 5$, pyridoxine hydrochloride $2 \cdot 0$, calcium-D-pantothenate 20 , niacin 100 , menadione $1 \cdot 0$, pteroylmonoglutamic acid 20 , D-biotin 1.0 , cyanocobalamin (I mg triturate $/ \mathrm{g}$ ) $10 \cdot 0$, retinyl palmitate ( $138 \mathrm{mg} / \mathrm{g}$ water-soluble matrix) 100 , ergocalciferol $0 \cdot 05$.

for 15 min; Beckman Accuspin, AH-4 rotor; Beckman Instruments, Palo Alto, CA). After removal of the leucocytes by gentle aspiration, the erythrocytes were restored to the original blood volume with phosphate-buffered saline ( $9 \mathrm{~g}$ sodium chloride/1), $\mathrm{pH} \mathrm{7 \cdot 4}$. The livers were perfused in situ with ice-cold $0.15 \mathrm{M}$-potassium chloride to remove contaminating erythrocytes, weighed and stored temporarily on ice. A liver homogenate $(250 \mathrm{~g} / \mathrm{l})$ was prepared in deionized water using five strokes of a Potter Elvehjem homogenizer. Muscle tissue from the gastrocnemius and thigh muscles (biceps femoris and semitendinosus) was removed from both hind-legs, cleaned of tendon and connective tissue, and weighed. A muscle homogenate $(100 \mathrm{~g} / 1)$ in deionized water was prepared using a Polytron homogenizer (Brinkmann Inst. Co., Westburg, NY; 20 s with PT 1035 head).

On the day of death, GSH-Px activity in plasma, erythrocytes, liver and muscle was assayed using the coupled assay procedure (Lawrence et al. 1974) with hydrogen peroxide so that only the Se-dependent GSH-Px activity was measured (Lawrence et al. 1978). One EU is that amount of GSH-Px that will oxidize $1 \mu \mathrm{mol}$ glutathione/min under the conditions described by Lawrence et al. (1974). Protein concentration was determined as described by Lowry et al. (1951) the next day. Plasma and erythrocytes were stored on ice, and liver and muscle tissue were frozen at $-85^{\circ}$ for later Se analysis. Se concentration was determined using the wet digestion and fluorometric analysis as described previously (Waschulewski \& Sunde, 1988).

\section{Statistical analysis}

The values from rats killed on a given day were compared using analysis of variance (treatment $2 \mathrm{df}$, error $15 \mathrm{df}$ ) to determine if significant differences between groups were present. If significant, Duncan's multiple-range test (Steel \& Torrie, 1960) was applied to determine which treatment means were significantly different using the pooled-error meansquare term to calculate the least-significant ranges. Kramer's modification of Duncan's multiple-range test (Steel \& Torrie, 1960) was used when missing values resulted in unequal class sizes. A significance level of $P<0.05$ was used for all tests unless otherwise noted. The rate of increase of muscle Se was calculated by linear regression analysis using the individual values, and significant differences in the rate (slope) due to dietary methionine treatment were tested using analysis of covariance (Zar, 1974). 
Table 2. Effect of dietary methionine on rat body-weight, liver weight and liver as a percentage of body-weight

(Mean values with their standard errors for six rats)

\begin{tabular}{|c|c|c|c|c|c|c|c|c|}
\hline \multirow{3}{*}{$\begin{array}{l}\text { Dietary methionine* } \\
\qquad(\mathrm{g} / \mathrm{kg})\end{array}$} & \multicolumn{8}{|c|}{ Day of experiment } \\
\hline & \multicolumn{2}{|c|}{3} & \multicolumn{2}{|c|}{6} & \multicolumn{2}{|c|}{13} & \multicolumn{2}{|c|}{20} \\
\hline & Mean & $\mathrm{SE}$ & Mean & $\mathrm{SE}$ & Mean & $\mathrm{SE}$ & Mean & $\mathrm{SE}$ \\
\hline \multicolumn{9}{|c|}{ Body-weight (g) } \\
\hline 0 & $71^{\mathrm{a}}$ & 1.4 & $82^{\mathrm{a}}$ & $1 \cdot 4$ & $116^{\mathrm{a}}$ & $3 \cdot 4$ & $148^{\mathrm{a}}$ & $5 \cdot 4$ \\
\hline 4 & $75^{\mathrm{b}}$ & $1 \cdot 3$ & $94^{\mathrm{b}}$ & $1 \cdot 4$ & $158^{b}$ & $2 \cdot 5$ & $209^{\mathrm{h}}$ & $5 \cdot 8$ \\
\hline 9 & $76^{\mathrm{b}}$ & 1.5 & $93^{\mathrm{b}}$ & $2 \cdot 2$ & $158^{b}$ & 3.4 & $212^{\mathrm{b}}$ & 32 \\
\hline \multicolumn{9}{|c|}{ Liver weight (g) } \\
\hline 0 & $3 \cdot 0^{\mathrm{a}}$ & $0 \cdot 3$ & $3 \cdot 9^{\mathrm{s}}$ & $0 \cdot 2$ & $6 \cdot 1^{\mathrm{a}}$ & 0.5 & $8 \cdot 6^{2}$ & 0.5 \\
\hline 4 & $3 \cdot 4^{a}$ & $0 \cdot 3$ & $5 \cdot 0^{\mathrm{b}}$ & 0.2 & $9 \cdot 1^{\mathrm{b}}$ & $0 \cdot 3$ & $13 \cdot 5^{b}$ & $0 \cdot 5$ \\
\hline 9 & $3 \cdot 8^{\mathrm{a}}$ & $0 \cdot 3$ & $4 \cdot 6^{\mathrm{a}, \mathrm{b}}$ & $0 \cdot 4$ & $10 \cdot 1^{b}$ & 0.4 & $13 \cdot 2^{b}$ & $0 \cdot 3$ \\
\hline \multicolumn{9}{|c|}{ Liver ( $\%$ body-weight $) \dagger$} \\
\hline 0 & $4 \cdot 2^{\mathrm{a}}$ & $0 \cdot 2$ & $4 \cdot 9^{\mathrm{a}}$ & 0.2 & $5 \cdot 2^{\mathrm{a}}$ & $0 \cdot 2$ & $5 \cdot 8^{a}$ & $0 \cdot 1$ \\
\hline 4 & $4 \cdot 4^{a}$ & $0 \cdot 3$ & $5 \cdot 6^{\mathrm{a}}$ & 0.3 & $5 \cdot 8^{b}$ & 0.1 & $6.5^{\mathrm{b}}$ & 0.2 \\
\hline 9 & $49^{a}$ & 0.3 & $5 \cdot 1^{a}$ & 0.3 & $6 \cdot 3^{c}$ & 0.2 & $6 \cdot 2^{\mathrm{a}, \mathrm{b}}$ & 0.2 \\
\hline
\end{tabular}

a, b, c Means in the same vertical column with unlike superscript letters are significantly different: $P<0.05$.

* Rats were supplemented with 0,4 or $9 \mathrm{~g}$ DL-methionine/ $\mathrm{kg}$ diet for $20 \mathrm{~d}$ as described on $\mathrm{p}$. 58 .

$\dagger$ At day 0 , the initial value was $4 \cdot 3$ (SE $0 \cdot 2$ ) $\%$.

\section{RESULTS}

\section{Growth and liver weight}

When 22-d-old rats were given $0.5 \mathrm{mg} \mathrm{Se}$ as [Se]Met $/ \mathrm{kg}$ in a torula yeast-based diet and supplemented with 0,4 or $9 \mathrm{~g}$ methionine $/ \mathrm{kg}$, the methionine-deficient rats were significantly smaller than the methionine-supplemented rats $3 \mathrm{~d}$ or more after the start of the dietary treatment (Table 2). Over the $20 \mathrm{~d}$ experimental period, the rats grew at an average of $4 \cdot 1,7 \cdot 4$ or $7 \cdot 3 \mathrm{~g} / \mathrm{d}$ with 0,4 and $9 \mathrm{~g}$ methionine/ $\mathrm{kg}$ supplementation respectively. The weights of the 4 and $9 \mathrm{~g}$ methionine $/ \mathrm{kg}$ supplemented rats were not significantly different $(P>0.05)$ during the course of the experiment. The liver weights (Table 2$)$ of the methionine-deficient rats were also significantly smaller than those of the 4 and $9 \mathrm{~g}$ methionine $/ \mathrm{kg}$ supplemented rats 13 and $20 \mathrm{~d}$ after the start of the experiment. When the liver weights were expressed as a percentage of body-weight (Table 2), however, the only significant difference was a $12 \%$ increase in this value at days 13 and 20 for the $4 \mathrm{~g}$ methionine $/ \mathrm{kg}$ group and a $21 \%$ increase only at day 13 for the $9 \mathrm{~g}$ methionine $/ \mathrm{kg}$ group when compared with the methionine-deficient animals. Thus feeding the methioninedeficient diet resulted in a decrease in the rate of growth, showing that the rats were methionine deficient, but methionine deficiency did not result in substantial changes in relative liver size in this experiment.

\section{Plasma, erythrocyte, liver and muscle Se}

Supplementation of weanling rats with $0.5 \mathrm{mg} \mathrm{Se}$ as [Se]Met $/ \mathrm{kg}$ for $20 \mathrm{~d}$ resulted in increases in plasma, erythrocyte, liver and muscle Se (Fig. 1) for all three dietarymethionine groups. The magnitude of increase, however, was different for different tissues and was modulated by the level of dietary methionine. Plasma Se (Fig. 1(a)) increased 1.7-, 

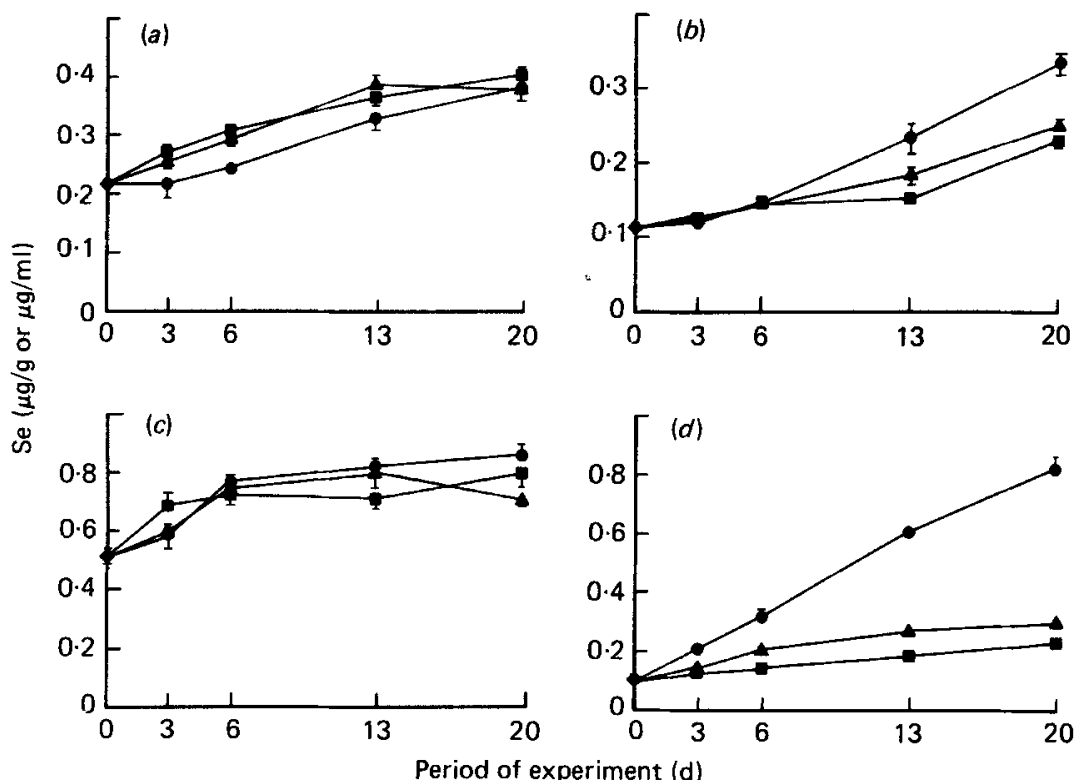

Fig. 1. The effect of selenomethionine ([Se]Met) and supplementary methionine on (a) plasma, $(b)$ erythrocytes, $(c)$ liver and $(d)$ muscle selenium. Weanling rats were given $0.5 \mathrm{mg}$ Se as [Se]Met $/ \mathrm{kg}$ and supplemented with $0(\bigcirc), 4(\Delta)$ or $9(\square) \mathrm{g}$ DL-methionine/ $\mathrm{kg}$ for $20 \mathrm{~d}$. Se concentration is expressed as $\mu \mathrm{g} \mathrm{Se} / \mathrm{ml}$ plasma or $\mu \mathrm{g} / \mathrm{g}$ tissue. Values are means with their standard errors represented by vertical bars for six rats.

1.7- or 1.9 -fold with 0,4 or $9 \mathrm{~g}$ methionine $/ \mathrm{kg}$ supplementation respectively, over the $20 \mathrm{~d}$ experiment. At days 3 and 6, plasma Se was significantly higher in rats supplemented with $9 \mathrm{~g}$ methionine $/ \mathrm{kg}$ compared with $0 \mathrm{~g}$ methionine $/ \mathrm{kg}$, but this difference disappeared by day 20. Erythrocyte Se concentration (Fig. 1(b)) increased 3.0-, 2·3- or 2·1-fold when animals were supplemented with 0,4 or $9 \mathrm{~g}$ methionine $/ \mathrm{kg}$ respectively. The Se concentration was significantly higher in the methionine-deficient group compared with the methionine-supplemented groups at days 13 and 20, but not at days 3 and 6 . Liver Se (Fig. $1(c)$ ) increased 1.7-, 1.4- or 1.6-fold with 0,4 or $9 \mathrm{~g}$ methionine $/ \mathrm{kg}$ supplementation respectively, during the $20 \mathrm{~d}$ experiment. The majority of this increase in liver Se occurred by day 6 for all methionine-treatment groups. At day 13, liver Se was significantly higher in the methionine-deficient animals than in the methionine-supplemented animals, but at day 20 the only significant difference was between the methionine-deficient and $4 \mathrm{~g}$ methionine/kg groups. During the $20 \mathrm{~d}$ [Se]Met supplementation period, muscle Se (Fig. $1(d)$ ) increased $8 \cdot 6-, 3 \cdot 1$ - or $2 \cdot 4$-fold with 0,4 or $9 \mathrm{~g}$ methionine $/ \mathrm{kg}$ supplementation respectively. At day 3 and later, significant increases in muscle Se were observed in methionine-deficient animals compared with methionine-supplemented animals. Muscle Se increased linearly $(r 0.979)$ over the $20 \mathrm{~d}$ at a rate of $0.0368 \mu \mathrm{g} \mathrm{Se} / \mathrm{g}$ tissue per $\mathrm{d}$ in the methionine-deficient group. With 4 and $9 \mathrm{~g}$ methionine/ $\mathrm{kg}$ supplementation, muscle Se also increased linearly $(r 0.935$ and 0.879 respectively) but at reduced rates (0.0099 and $0.0067 \mu \mathrm{g} \mathrm{Se} / \mathrm{g}$ tissue per d respectively) compared with methionine-deficient rats.

\section{Plasma, liver and muscle GSH-PX}

The level of dietary methionine had a significant effect on plasma, liver and muscle GSHPx activity when $0.5 \mathrm{mg}$ Se as [Se]Met $/ \mathrm{kg}$ was given to weanling rats (Fig. 2). Plasma GSHPx activity (Fig. 2(a)) decreased $66 \%$ in the first $3 \mathrm{~d}$ after the start of the methionine- 


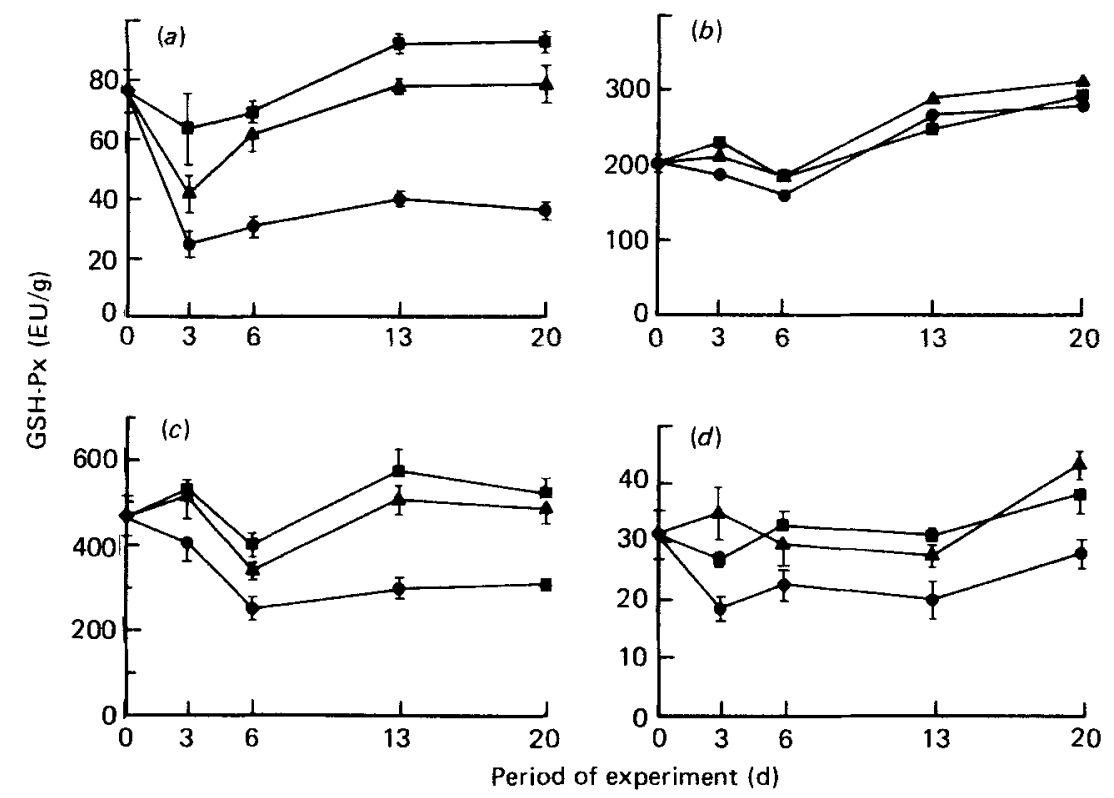

Fig. 2. The effect of selenomethionine ([Se]Met) and supplementary methionine on (a) plasma, $(b)$ erythrocytes, $(c)$ liver and $(d)$ muscle glutathione peroxidase (EC 1.11.1.9; GSH-Px) activity. Weanling rats were given $0.5 \mathrm{mg} \mathrm{Se}$ as [Se]Met/ $\mathrm{kg}$ and supplemented with $0(\boldsymbol{O}), 4(\mathbf{A})$ or $9(\mathbf{C}) \mathrm{g}$ DL-methionine/ $\mathrm{kg}$ for $20 \mathrm{~d}$. GSH-Px activity is expressed as EU/g protein, where $1 \mathrm{EU}$ is $1 \mu \mathrm{mol}$ glutathione oxidized/ min as described by Lawrence et al. (1974). Values are means with their standard errors represented by vertical bars for six rats.

deficient diet, and then plasma GSH-Px activity remained at this level for the rest of the experiment. Supplementation of the [Se]Met diet with $4 \mathrm{~g}$ methionine/ $\mathrm{kg}$ lessened the magnitude of the day 3 decrease in GSH-Px activity to $45 \%$ of the initial activity, and then resulted in restoration of plasma GSH-Px activity such that the GSH-Px activity returned to the initial level $13 \mathrm{~d}$ after the start of the [Se]Met supplementation period. Supplementation with $9 \mathrm{~g}$ methionine $/ \mathrm{kg}$ resulted in only a small, insignificant reduction $(P>0.05)$ in GSH-Px activity at day 3 , and it elicited a significant increase in GSH-Px activity at days 13 and $20(P<0 \cdot 05)$. Erythrocyte GSH-Px (Fig. 2(b)) increased 1.3-, 1.5and $1 \cdot 4$-fold in the 0,4 and $9 \mathrm{~g}$ methionine/ $\mathrm{kg}$ treated animals respectively, over the $20 \mathrm{~d}$ experiment, and dietary methionine did not have a significant effect on GSH-Px synthesis. Liver GSH-Px (Fig. 2(c)), however, significantly decreased $53 \%$ within the first $6 \mathrm{~d}$ when the diet contained no supplemental methionine, and then remained at this level for the remainder of the experiment. Despite fluctuations in enzyme activity, no overall change in liver GSH-Px activity was observed in animals supplemented with 4 or $9 \mathrm{~g}$ methionine $/ \mathrm{kg}$ for $20 \mathrm{~d}$. Only the GSH-Px activity at day 6 was significantly lower than the initial or final liver GSH-Px activities for both 4 and $9 \mathrm{~g}$ methionine/ $\mathrm{kg}$ supplemented rats. Muscle GSHPx (Fig. $2(d)$ ) only decreased $12 \%$ in rats fed on the methionine-deficient diet over the $20 \mathrm{~d}$ experiment. In contrast to plasma and liver, muscle GSH-Px activity did not change significantly during the first $13 \mathrm{~d}$ when the rats were supplemented with 4 or $9 \mathrm{~g}$ methionine $/ \mathrm{kg}$, but then muscle GSH-Px activity increased significantly during the last week.

\section{Percentage of tissue Se associated with GSH-PX}

To further characterize the influence of dietary methionine on the change in tissue Se distribution during the course of the experiment, the percentage of the total tissue $\mathrm{Se}$ 


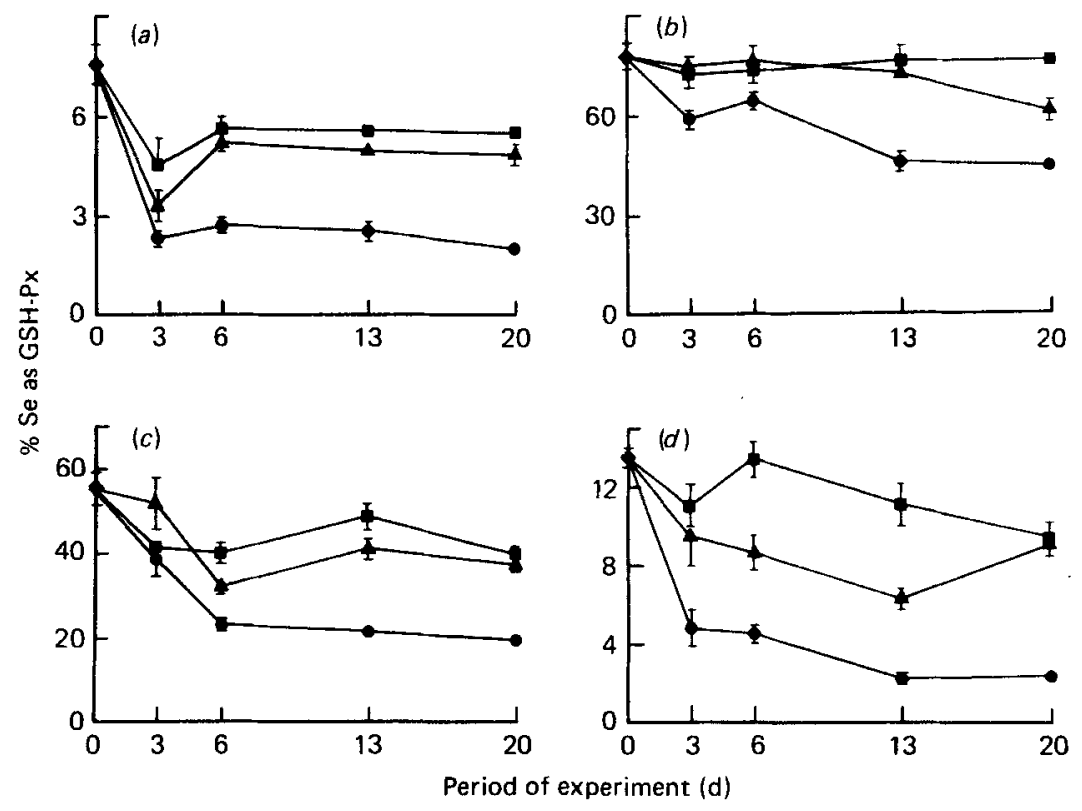

Fig. 3. Percentage of the total tissue selenium present as $\mathrm{Se}$ in glutathione peroxidase $(E C$ 1.11.1.9; GSH-Px) for (a) plasma, (b) erythrocytes, (c) liver and $(d)$ muscle. The value of $4.63 \times 10^{-3} \mu \mathrm{g} \mathrm{Se} / \mathrm{EU}$ GSH-Px for purified rat liver GSH-Px (see below), and the measured tissue Se (Fig. 1) and GSH-Px activity (Fig. 2) were used to calculate the percentage of the total Se in each sample that was present as $\mathrm{Se}$ in GSH-Px. Weanling rats were given $0.5 \mathrm{mg}$ Se as [Se]Met/ $\mathrm{kg}$ and supplemented with $0(\boldsymbol{O}), 4(\boldsymbol{A})$ or 9 ( $) \mathrm{g}$ DL-methionine/ $\mathrm{kg}$ for $20 \mathrm{~d}$. Values are means with their standard errors represented by vertical bars for six rats.

associated with GSH-Px was calculated. The enzyme activity of purified rat liver GSH-Px (853 EU/mg protein; Sunde \& Evenson, 1987), the molecular weight of GSH-Px $(80000$ $\mathrm{g} / \mathrm{mol})$ and the Se content of GSH-Px $(4 \mathrm{~g}$ atom $/ \mathrm{mol})$ were used to calculate a value of $4.63 \times 10^{-3} \mu \mathrm{g} \mathrm{Se} / \mathrm{EU} \mathrm{GSH}-\mathrm{Px}$ when assayed under these conditions (Waschulewski \& Sunde, 1988). Using this constant and the measured values for GSH-Px activity (EU/g protein), Se ( $\mu \mathrm{g} / \mathrm{g}$ tissue) and protein (mg protein $/ \mathrm{g}$ tissue) for each sample, the values in Figs 1 and 2 were combined to provide the values presented in Fig. 3. Initially $8 \%$ of plasma Se, $55 \%$ of liver Se and $14 \%$ of muscle Se could be accounted for by the GSH-Px activity in these tissues. After giving weanling rats $0.5 \mathrm{mg} \mathrm{Se}$ as [Se]Met $/ \mathrm{kg}$ for $20 \mathrm{~d}$, the percentage of tissue Se present as GSH-Px decreased in all tissues except erythrocytes for all dietary methionine treatments (Fig. 3). The magnitude of decrease, however, was affected by the level of dietary methionine as seen in the graded responses to dietary methionine level for the percentage of plasma, liver and muscle Se present as GSH-Px. The percentage of plasma Se present as GSH-Px (Fig. 3(a)) decreased to $2.0 \%$ in the first $3 \mathrm{~d}$ when [Se]Met was added to a methionine-deficient diet and then stayed at this level during the remainder of the experiment. Supplementation of the diet with 4 or 9 g methionine $/ \mathrm{kg}$ lessened the magnitude of the day 3 decrease in the percentage of plasma Se present as GSH-Px, such that the percentage of plasma Se as GSH-Px was significantly higher in methionine-supplemented than in methionine-deficient rats for days 3-20. The percentage of erythrocyte Se (Fig. 3(b)) present as GSH-Px decreased in the methionine-deficient group, whereas only a small reduction was detected in the $4 \mathrm{~g}$ methionine $/ \mathrm{kg}$ group and no difference was found in the $9 \mathrm{~g}$ methionine/ $\mathrm{kg}$ group. Liver Se present as GSH-Px also showed a graded response to the level of dietary methionine (Fig. 3(c)). This percentage 
decreased from 55 to $19 \%$ within the first $6 \mathrm{~d}$ when the [Se]Met was added to the methionine-deficient diet, and then remained at this level throughout the rest of the experiment. Supplementation of the diet with 4 or $9 \mathrm{~g}$ methionine $/ \mathrm{kg}$ resulted in a significantly higher percentage of liver Se associated with GSH-Px at days 6-20 when compared with that in the methionine-deficient group. The percentage of muscle Se present as GSH-Px (Fig. 3(d)) decreased to $2 \%$ in the methionine-deficient rats by day 20 of the experiment, whereas this percentage was $10 \%$ in rats supplemented with methionine for $20 \mathrm{~d}$. At days 3, 6 and 13 the percentage of muscle Se present as GSH-Px was significantly higher in $4 \mathrm{~g}$ methionine $/ \mathrm{kg}$-supplemented rats compared with methionine-deficient rats, and this percentage for $9 \mathrm{~g}$ methionine $/ \mathrm{kg}$-supplemented rats was also significantly higher than that for $4 \mathrm{~g}$ methionine $/ \mathrm{kg}$-supplemented rats at days 3,6 and 13 . Overall, the percentage of tissue Se associated with GSH-Px was significantly lower in methioninedeficient rats in all tissues compared with methionine-supplemented rats, indicating that less Se was present as GSH-Px in the methionine-deficient rats.

\section{DISCUSSION}

This experiment investigated the effect of dietary methionine on the utilization of Se from dietary [Se]Met as measured by tissue Se concentration, GSH-Px activity and calculation of the percentage of Se present as GSH-Px in plasma, erythrocytes, liver and muscle. Tissue Se increased with all three dietary methionine treatments. Significantly higher tissue Se concentrations were detected in erythrocytes and muscle when the [Se]Met was provided in a methionine-deficient diet compared with 4 or $9 \mathrm{~g}$ methionine $/ \mathrm{kg}$-supplemented diets, but final plasma and liver Se concentrations were not significantly different amongst the different dietary methionine treatments. In contrast to these increases in tissue Se, GSH-Px activity dramatically decreased in plasma (53\%) and liver $(33 \%)$, decreased nonsignificantly in muscle $(12 \%)$ and increased in erythrocytes when animals were given a methionine-deficient diet supplemented with $0.5 \mathrm{mg} \mathrm{Se}$ as [Se]Met $/ \mathrm{kg}$ for $20 \mathrm{~d}$. Methionine supplementation lessened or prevented the initial declines in GSH-Px activity in plasma, liver and muscle, and resulted in significantly higher GSH-Px activities in plasma, liver and muscle at the end of the experiment when compared with methionine-deficient rats.

The basal diet resulted in a growth depression of $58 \%$ compared with the methioninesupplemented rats, indicating that the diet was deficient in methionine (Table 2). There were also correspondingly reduced liver weights, but the relative effect of dietary methionine on body-weight and liver weight was such that at day 20 the liver weight of the $4 \mathrm{~g}$ methionine $/ \mathrm{kg}$-supplemented rats was only $12 \%$ above that of the methionine-deficient rats when expressed as a percentage of body-weight. These changes in body-weight and liver weight cannot be the direct cause of the observed changes in tissue Se and GSH-Px activity; increased growth alone would result in dilution of tissue Se and yet tissue Se levels increased in all treatment groups. Similarly, dilution of tissue GSH-Px cannot be the cause of the decreased tissue GSH-Px activities because the largest decreases were observed in the methionine-deficient rats which had the smallest increases in body-weight and liver weight. Thus the observed changes in Se concentration and GSH-Px activity were due to the effect of dietary methionine on Se metabolism and not directly to altered growth rates.

Dietary [Se]Met supplementation has been reported to lead to higher tissue Se levels than dietary selenite supplementation in rats (Cary et al. 1973), chickens (Osman \& Latshaw, 1976) and man (Thomson et al. 1982). In vitro experiments have shown that $\left[{ }^{75} \mathrm{Se}\right] \mathrm{Met}$ initially labelled a large number of cytosolic proteins in mouse fibroblasts before more slowly labelling GSH-Px with ${ }^{75} \mathrm{Se}$, whereas $\left[{ }^{75} \mathrm{Se}\right]$ selenite just labelled GSH-Px (White \& Hoekstra, 1979). In vivo experiments have shown that $\left[{ }^{75} \mathrm{Se}\right] \mathrm{Met}$ injection into rats 
predominantly labelled haemoglobin whereas $\left[{ }^{75}\right.$ Se]selenite injection predominantly labelled GSH-Px (Beilstein \& Whanger, 1986). In studies examining the effect of Se supplementation on GSH-Px activity, dietary [Se]Met and selenite supplementation of Sedeficient rats increased tissue GSH-Px to the same extent when administered at $2 \mathrm{mg} \mathrm{Se}$ / $\mathrm{kg}$ to vitamin $\mathrm{B}_{6}$-adequate rats (Yasumoto et al. 1979). A single oral dose of $300 \mu \mathrm{g}$ Se as selenite or [Se]Met equally induced GSH-Px activity within $50 \mathrm{~h}$ (Pierce \& Tappel, 1977). These experiments, however, used amounts of Se which exceed the dietary Se requirement $(0.1 \mathrm{mg} \mathrm{Se} / \mathrm{kg}) 20$-fold and 200 -fold if fed on a daily basis, and thus these high levels most likely prevented detection of any metabolic differences that might have been detected with levels nearer to the dietary Se requirement. In experiments with levels of Se near the dietary requirement, [Se]Met was reported to have $40 \%$ of the ability of selenite to provide Se for GSH-Px synthesis when added at $0.2 \mathrm{mg} / \mathrm{kg}$ Se in a $200 \mathrm{~g}$ casein $/ \mathrm{kg}$ based diet (Sunde $e t$ al. $1981 \mathrm{~b}$ ). Increasing the dietary Se level to $2.0 \mathrm{mg} / \mathrm{kg}$ or addition of $2.5 \mathrm{~g}$ methionine $/ \mathrm{kg}$ to the diet resulted in equal abilities of [Se]Met and selenite to provide Se for GSH-Px.

We also observed decreased tissue GSH-Px levels in spite of increasing tissue Se concentrations in our previous study (Waschulewski \& Sunde, 1988). Plasma, liver and muscle GSH-Px decreased $43-50 \%$ in spite of 2.6-, 2-5- and 2-2-fold increases in tissue Se respectively (Waschulewski \& Sunde, 1988), but the magnitudes of Se deposition as well as the percentage decrease in GSH-Px activity were different between these two studies. Initial tissue $\mathrm{Se}$ concentrations in the present study were 1.3- and 1.5-fold higher in plasma and liver respectively, than in the previous study, but initial muscle Se in the present study was snly $33 \%$ of that observed in the earlier study (Waschulewski \& Sunde, 1988). This low initial muscle Se concentration was apparently one of the reasons why muscle Se increased as much as $8 \cdot 6$-fold in the present study when methionine-deficient rats were supplemented with $0.5 \mathrm{mg} \mathrm{Se}$ as [Se]Met $/ \mathrm{kg}$. The cause of the differences in initial tissue Se and GSH-Px activity between these two studies is not known, but the differences may have been due to different levels and forms of Se in the diet and in the tissues of the dams of these two sets of weanling rats.

The initial declines in liver, plasma and muscle GSH-Px activity occurred during the period of adaptation of the rats to the different dietary methionine levels. Once the animals were adapted to the dietary methionine level, which takes 3-4 d (Aguilar et al. 1972), GSHPx activity was restored in methionine-supplemented animals over the remainder of the experiment whereas GSH-Px activity in methionine-deficient rats remained at reduced levels. In contrast to these graded responses in plasma, liver and muscle to methionine treatment, erythrocyte GSH-Px activity increased in all methionine-treatment groups. The long erythrocyte lifespan (60 d) and lack of protein turnover in mature erythrocytes (Berlin, 1964) may have been the cause of the observed lack of an initial decrease in erythrocyte GSH-Px activity as well as the slow increase in erythrocyte GSH-Px activity in all methionine-treatment groups over the $20 \mathrm{~d}$ experiment.

The interaction of dietary methionine and [Se]Met can be explained because these amino acids have common metabolic pathways. The similar covalent radii of Se and S allow [Se]Met to be an excellent analogue for methionine in biochemical reactions. For instance, [Se]Met is transported by the same intestinal transport system as methionine (McConnell $\&$ Cho, 1965), it is readily esterified to tRNA ${ }^{\text {Met }}\left(K_{m} 11 v .7 \mu \mathrm{M}\right.$ for methionine, Hoffman et al. 1970), and it can substitute for methionine during protein synthesis in eukaryotes (McConnell \& Hoffman, 1972). Thus [Se]Met clearly can be metabolized by the same enzymes that incorporate methionine into protein. It is also likely that [Se]Met follows the methionine catabolic pathways until one of the C-Se bonds is broken (Sunde, 1984). These common pathways thus can be combined into a diagram of Se metabolism (Fig. 4) that can be used to illustrate and summarize the two fates of dietary [Se]Met. After absorption, 


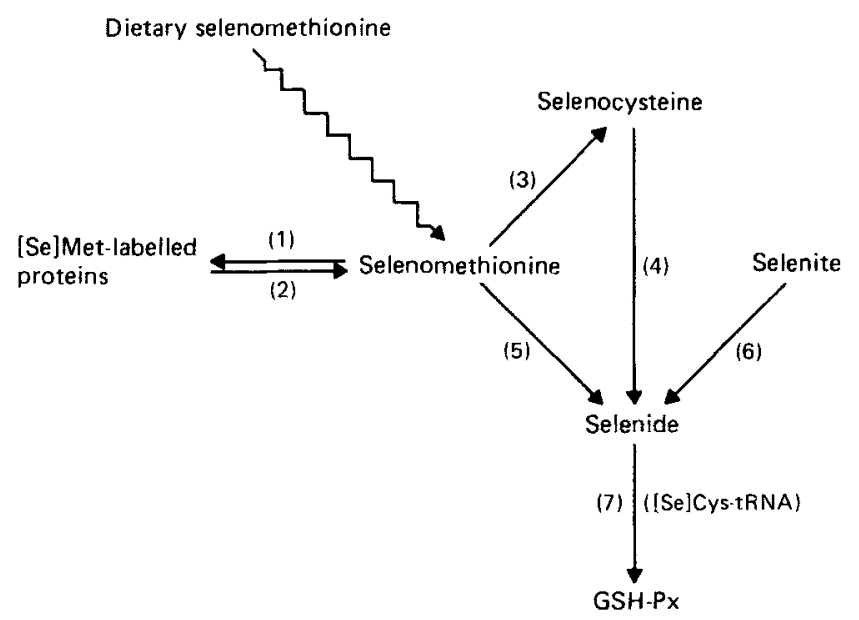

Fig. 4. Proposed diagram of the metabolism of selenomethionine ([Se]Met) and other selenium compounds. Reaction 1, free [Se]Met, arising from dietary [Se]Met or from protein turnover, is incorporated into proteins in place of methionine as mediated by tRNA ${ }^{\text {Met }}$ (McConnell \& Hoffman, 1972); reaction 2, release of [Se]Met during protein turnover; reaction 3, transsulphuration pathway, analogous to sulphur metabolism; reaction 4, selenocysteine lyase and subsequent reduction of Se to selenide (Esaki ef al. 1982); reaction 5, transamination pathway, analogous to the methionine transamination pathway (Steele \& Benevenga, 1978); reaction 6, glutathione-dependent Se reduction pathway (Hsieh \& Ganther, 1977); reaction 7, hypothetical cotranslational incorporation of Se into glutathione peroxidase (EC 1.11.1.9; GSH-Px) and other selenoproteins from inorganic Se and serine, as mediated by a selenocysteine-tRNA (Sunde \& Evenson, 1987).

transport and cellular uptake, [Se]Met from the diet can be esterified to tRNA ${ }^{\text {Met }}$ and incorporated into protein in place of methionine (reaction 1), or it can be degraded by one of the two methionine catabolic pathways. The common textbook 'methionine transsulphuration pathway' would convert [Se]Met to selenocysteine (reaction 3) via selenocystathionine. Then selenocysteine lyase (reaction 4), the only enzyme known to be specific for selenocysteine (Esaki et al. 1982), would release selenide from selenocysteine. [Se]Met, however, may also be catabolized by the 'methionine transamination' pathway (reaction 5) first described by Steele \& Benevenga (1978), which also would release selenide. Se from [Se]Met would thus be available for co-translational incorporation into GSH-Px and other selenoproteins (reaction 7) as proposed by Sunde \& Evenson (1987). Protein turnover (reaction 2) would release [Se]Met from body proteins which can be reincorporated into protein or catabolized.

The rate of methionine catabolism increases substantially as dietary methionine is raised from deficient to adequate levels (Aguilar et al. 1972), and so the results observed in the present experiment can be explained logically if dietary methionine level has a similar effect on [Se]Met catabolism. In rats fed on a methionine-deficient diet, methionine would be the rate-limiting amino acid for protein synthesis and so [Se]Met would preferentially be incorporated into protein in place of methionine. This would result in elevated tissue $\mathrm{Se}$ levels in methionine-deficient rats relative to the methionine-supplemented rats, especially in muscle. This hypothesis also suggests that methionine deficiency reduces the rate of [Se]Met catabolism such that less Se is available for GSH-Px synthesis. Adequate or high dietary levels of methionine, in contrast, would result in higher rates of methionine and [Se]Met catabolism which would release more Se for GSH-Px synthesis. These effects on tissue Se and GSH-Px activity would thus lead to the alterations in the percentage of tissue Se present as GSH-Px that were observed in the present experiment. 
The percentage of tissue Se associated with GSH-Px was calculated from the enzyme activity of purified rat liver GSH-Px. This resulting estimate should thus be rather accurate for liver, and the calculated values compare favourably with those reported previously for liver in rats and other species (Sunde et al. 1978; Beilstein \& Whanger, 1983). The estimated initial percentage of total Se as GSH-Px in muscle $(13 \%)$ is much lower than that in liver $(55 \%)$, which is as expected because of the relatively low muscle GSH-Px activity. The calculated percentage of plasma Se present as GSH-Px declined from 7 to $2.8 \%$ in methionine-deficient animals, whereas in methionine-supplemented animals it remained at $5 \%$. The true percentage of plasma Se present as GSH-Px may be 10 -fold higher than that estimated by these calculations (based on liver GSH-Px) because the specific activity of plasma GSH-Px has been recently reported to be $10 \%$ of that of erythrocyte GSH-Px (Takahashi et al. 1987). The relative effects of methionine on the percentage of plasma Se present as GSH-Px, however, would remain the same when calculated using either specific activity.

These findings and the resulting diagram of Se metabolism are based on experiments with rats using defined diets and chemically pure forms of Se. The extrapolation of these results to a model of human Se metabolism may or may not be straightforward. For instance, a recent study has shown that methionine $(0.5 \mathrm{~g}$ as DL-methionine/d) had no apparent differential effect on the bioavailability of [Se]Met $v$. selenite for GSH-Px synthesis in human beings given $50 \mu \mathrm{g} \mathrm{Se} / \mathrm{d}$ for 8 weeks (Luo et al. 1987). In control subjects not receiving Se supplements, however, erythrocyte GSH-Px activity was increased by the methionine supplementation, suggesting that additional methionine increased the utilization of the Se in the basal diet for GSH-Px synthesis. Thus methionine supplementation might increase the bioavailability of Se from low-Se foods, as suggested by these rat experiments, but it may not affect [Se]Met bioavailability at higher Se supplementation levels.

In conclusion, the present study demonstrates firstly that the level of dietary methionine can dramatically modulate the availability of Se from dietary [Se]Met for synthesis of selenoproteins like GSH-Px. Methionine deficiency substantially decreased the utilization of Se from dietary [Se]Met for GSH-Px synthesis, and it led to preferential incorporation of Se into tissues in a form other than as GSH-Px. Secondly, supplemental methionine significantly increased utilization of Se from dietary [Se]Met for maintenance of tissue GSH-Px levels. Because the present study shows that metabolism of [Se]Met to biochemically active forms of Se (such as GSH-Px) is impaired in rats when dietary methionine is deficient, and because methionine can be a limiting amino acid in typical human diets, the present experiment further suggests that [Se]Met may not be the optimum Se compound to use for human supplementation.

The authors wish to thank J. Seminoff for his technical assistance, Dr B. L. Reid and Dr D. J. McNamara for the use of their wet-digestion hoods and J. K. Evenson for her helpful discussions on Se metabolism. This work was supported in part by the University of Arizona Agricultural Experiment Station, and by grants from the National Institute of Diabetes and Digestive and Kidney Diseases (DK 32942), the USDA Human Requirements for Nutrients Program (85-CRCR-1-1583) and the Biomedical Research Support Grant program (SO7 RR07002).

\section{REFERENCES}

Aguilar, T. S., Harper, A. E. \& Benevenga, N. J. (1972). Journal of Nutrition 102, 1199-1208.

Beilstein, M. A. \& Whanger, P. D. (1983). Journal of Nutrution 113, 2138-2146.

Beilstein, M. A. \& Whanger, P. D. (1986). Journal of Nutrition 116, 1701-1710.

Berlin, N. I. (1964). In The Red Blood Cell, pp. 423-450 [C. Bishop and D. M. Surgenor, editors]. New York: Academic Press. 
Cary, E. E., Allaway, W. H. \& Miller, M. (1973). Journal of Animal Science 36, 285-292.

Chow, C. K. \& Tappel, A. L. (1974). Journal of Nutrition 104, 444-451.

Esaki, N., Nakamura, T., Tanaka, H. \& Soda, K. (1982). Journal of Biological Chemistry 257, $4386-4391$.

Hafeman, D. G., Sunde, R. A. \& Hoekstra, W. G. (1974). Joumal of Nutrition 104, 580-587.

Hoffman, J. L., McConnell, K. P. \& Carpenter, D. R. (1970). Biochimica et Biophysica Acta 199, $531-534$.

Hsieh, H. S. \& Ganther, H. E. (1977). Biochimica et Biophysica Acta 497, 205-217.

Humaloja, T. \& Mykkanen, H. M. (1986). Journal of Nutrition 116, 142-148.

Knight, S. A. B. \& Sunde, R. A. (1987). Journal of Nutrition 117, 732-738.

Lawrence, R. A., Parkhill, L. K. \& Burk, R. F. (1978). Journal of Nutrition 108, 981-987.

Lawrence, R. A., Sunde, R. A., Schwartz, G. L. \& Hoekstra, W. G. (1974). Experimental Eye Research 18, 563-569.

Lowry, O. H., Rosebrough, N. J., Farr, A. L. \& Randall, R. J. (1951). Journal of Biological Chemistry 193, $265-275$.

Luo, X., Wei, H., Yang, C., Xing, J., Liu, X., Qiao, C., Feng, Y., Liu, J., Liu, Y., Wu, Q., Liu, X., Guo, J., Stoecker, B. J., Spallholz, J. E. \& Yang, S. P. (1987). In Selenium in Biology and Medicine, part A, pp. 436-444 [G. F. Combs, J. E. Spallholz, O. A. Levander and J. E. Oldfield, editors]. New York: AVI Books.

McConnell, K. P. \& Cho, G. J. (1965). American Journal of Physiology 208, 1191-1195.

McConnell, K. P. \& Hoffman, J. L. (1972). FEBS Letters 24, 60-62.

National Research Council (1978). Nutrient Requirements of Laboratory Animals, pp. 7-37. Washington, DC: National Academy Press.

Omaye, S. T. \& Tappel, A. L. (1974). Journal of Nutrition 104, 747-753.

Osman, M. \& Latshaw, J. D. (1976). Poultry Science 55, 987-994.

Pierce, S. \& Tappel, A. L. (1977). Journal of Nutrition 107, 475-479.

Robinson, M. F., Rea, H. M., Friend, G. M., Stewart, R. D. H., Snow, P. C. \& Thomson, C. D. (1978). British Journal of Nutrition 39, 589-600.

Steel, R. G. D. \& Torrie, J. H. (1960). Principles and Procedures of Statistics. New York: McGraw-Hill.

Steele, R. D. \& Benevenga, N. J. (1978). Journal of Biological Chemistry 253, $7844-7850$.

Sunde, R. A. (1984). Journal of the American Oil Chemists' Society 61, 1891-1900.

Sunde, R, A. \& Evenson, J. K. (1987). Journal of Biological Chemistry 262, 933-937.

Sunde, R. A., Ganther, H. E. \& Hoekstra, W. G. (1978). Federation Proceedings 37, 757, Abstr.

Sunde, R. A., Gutzke, G. E. \& Hoekstra, W. G. (1981 a). Journal of Nutrition 111, 76-86.

Sunde, R. A., Sonnenburg, W. K., Gutzke, G. E. \& Hoekstra, W. G. (1981 b). In Trace Element Metabolism in Man and Animals - 4, pp. 165-167 [J. M. Howell, J. M. Gawthorne and C. L. White, editors]. Canberra, Australia: Australian Academy of Science.

Takahashi, K., Avissar, N., Whitin, J. \& Cohen, H. (1987). Archives of Biochemistry and Biophysics 256, 677-686.

Thomson, C. D., Robinson, M. F., Campbell, D. R. \& Rea, H. M. (1982). American Journal of Clinical Nutrition 36, 24-31.

Thomson, C. D. \& Stewart, R. D. H. (1973). British Journal of Nutrition 30, 139-147.

Waschulewski, I. H. \& Sunde, R. A. (1988). Journal of Nutrition 118, 367-374.

White, C. L. \& Hoekstra, W. G. (1979). Biological Trace Element Research 1, 243-257.

Yasumoto, K., Iwami, K. \& Yoshida, M. (1979). Journal of Nutrition 109, 760-766.

Zar, J. H. (1974). Biostatistical Analysis. Englewood Cliff, NJ: Prentice-Hall. 